The $\delta 15 \mathrm{~N}$ values at most sites were fairly consistent with depth from the surface to the water table. There is no evidence from our data that denitrification is a significant process at any of the sites, with the possible exception of the Salinas Valley septic tank site. Thus, except for one site in the eight main test sites, the results demonstrate that measuring the $\delta^{15} \mathrm{~N}$ value immediately below the $\mathrm{NO}_{3}$ source can be an accurate indicator of the fingerprint of that source and that, under the conditions prevailing at these sites, the fingerprint will not change much during $\mathrm{NO}_{3}$ transport to groundwater. This is a very important conclusion for use of the $\mathrm{N}$ isotope technique to indicate sources of $\mathrm{NO}_{3}$ in groundwater. Nevertheless, users of the $\delta 15 \mathrm{~N}$ approach should be aware of the potential for mixing of $\delta^{15} \mathrm{~N}$ from multiple sources and of denitrification under some circumstances. Careful hydrogeologic characterization as well as sampling of both the unsaturated and saturated zones beneath potential sources are therefore typically required for successful application of the $\delta 15 \mathrm{~N}$ approach.

\section{D.E. Rolston, G.E. Fogg and M.E.}

Grismer are Professors of Soil Science, Hydrogeology and Hydrologic Science, respectively, and D.T. Louie is Staff Research Associate, Department of Land, Air and Water Resources, UC Davis; and D.L. Decker was postgraduate researcher and is presently graduate student, University of Nevada, Reno.

This research was supported by the California Water Resources Control Board, Interagency Agreement No. 1-155253-0, Monterey County Water Resources Agency and the U.S. Environmental Protection Agency Assistance Agreement Nos. 1009564-91-0 and C9009532-90-1.

The contents do not necessarily reflect the views and policies of the U.S. EPA, Monterey County or the California Water Resources Control Board. The authors appreciate the assistance of Heike Clausnitzer, Amy Wong, Mike Tolin and Brian Lindsay in laboratory analytical work and of Dr. Richard Mulvaney at the University of Illinois for $\delta^{5} \mathrm{~N}$ analysis.

\title{
How does water price affect irrigation technology adoption?
}

\author{
Gareth Green \\ Doug Parker \\ 口 David Sunding \\ $\square \quad$ Cliff Trotter $\square$
}

The use of water price or best management practices have been advocated by some commentators to induce adoption of low-volume irrigation technologies and to encourage water use efficiency. However, the method of water application Is only one of many inputs and constraints in agricultural production. Callfornia's highly diverse topography, soil types and variety of crops influence irrigation technology choices, therefore a policy mandating adoption of modern technologies is likely to have undesirable impacts. Crop type appears to be a major consideration in technology choice, as some technologies may be incompatible with some types of crops.

Continued urban population growth, heightened public awareness of the environmental benefits of in-stream water flows, and the virtual halt of water supply development in California have increased pressure on state and federal agencies to reallocate water away from agriculture. Many publicinterest groups and policy makers have suggested that growers could increase their use of low-volume irrigation technologies while maintaining current production levels. Some interests have even advocated imposing agricultural "best management practices" mandating the adoption of irrigation technologies. California growers have been criticized for their "irrational" and "inefficient" irrigation technology choices. It has been suggested that growers could maintain or increase their profitability while using

\author{
口 David Zilberman \\ Steve Collup
}

fewer resources. In this article, we assess whether technology choice is consistent with the assumption of profit maximization and, if so, determine which factors most influence technology choice.

Some commentators have advocated the use of water price as a policy tool to induce adoption of low-volume irrigation technologies and to encourage increased water-use efficiency. Specifically, environmentalists and many economists frequently assert that irrigation water should be priced to encourage adoption of modern technologies and reflect the value of water outside agriculture. However, the effectiveness of water price to achieve these goals may be limited because the method of water application is only one of many crucial inputs and constraints in agricultural production.

Our model demonstrates that large increases in the price of water generally encourage heavier reliance on drip and other low-pressure irrigation systems for certain crops, but may have only modest effects on adoption decisions for other modern irrigation technologies.

\section{Irrigation decisions in Arvin}

We selected the Arvin Edison Water Storage District, located in the southern San Joaquin Valley at the terminus of the Friant-Kern Canal, as our study area. There is wide variation in the types of irrigation technologies employed in the District: $25 \%$ furrow or flood, $49 \%$ high-pressure sprinkler and $26 \%$ low-pressure drip and microsprinkler (table 1). This variation makes the District ideal for analysis because there is a large amount of variability, yet the area is relatively 
small so the growers participate in many of the same markets and institutions. The District was initially formed in 1942 to contract for irrigation water, and in 1965 began percolating water to recharge the local groundwater aquifer. Because of the regional climate and favorable soils, growers in the District have diverse cropping patterns, as shown in table 1 . Grapes, citrus, deciduous, truck crops, potatoes and cotton make up $89 \%$ of the cultivated acres in the District.

We employed a standard multinomial logit statistical model to estimate the probability that a given irrigation technology would be adopted on a given field. Under this modeling framework, if a particular crop is irrigated almost solely under one irrigation technology, the summary statistics of the adoption probabilities will not be accurate. In the District, both potatoes and cotton use a high percentage of high-pressure sprinkler irrigation. In this case it is reasonable to combine potatoes with truck crops because they have similar production characteristics and are irrigated under each of the technologies considered. However, cotton is not similar to any of the other crop types and only uses gravity and high-pressure irrigation. Therefore it is necessary to remove cotton from the statistical analysis. Eliminating cotton and combining potatoes with truck crops does not substantially change the results.

The data on land allocation, irrigation technology, cost of water and water source were collected by the District. Our study includes truck crops (primarily fresh vegetables), citrus trees, deciduous trees and grape vineyards, which make up $76 \%$ of the planted acreage in the District. There are 1,493 field-level observations from the 1993 growing year in our data set, which includes all growers in the District who grow the crops listed. The remaining acreage is planted in cotton, grains, irrigated pasture and dry-land crops.

We consolidated irrigation technologies into three groups, based on the level of pressurization they require: furrow, flood and border, which are considered gravity technologies and are used on all types of crops; high-pressure sprinklers, which are used primarily on truck and deciduous crops; and low-pressure systems, including drip, microsprinklers and fan-jet systems, which are also used in each crop group. The use of high- and low-pressure irrigation technologies may reduce water use on fields with coarse soils or steep slope by increasing water application uniformity and reducing deep percolation and runoff.

There are several important points to be raised concerning low-volume technologies and perennial crops in the District. First, low-volume systems such as drip only wet a small area of soil. As a result, perennial crops under drip irrigation form a smaller root system than if gravity irrigation were used. Many growers feel that this makes the crop more susceptible to disease and increases the accumulation of salts, which reduces the attractiveness of these systems. Second, the cost of switching to low-volume technologies is high. This implies that the benefits from adopting low-volume technologies must be substantial in order to outweigh the cost of investing in the new technology, and that water savings alone may not justify technology adoption. Finally, many of the perennial crops in the District were established prior to the introduction of lowvolume systems.

Because different types of root systems develop under the different types of technologies, growers are reluctant to switch technologies on established perennial crops for fear of damaging them. This is most evident in vine crops, where $61 \%$ of the acreage employs gravity irrigation. However, in response to these criticisms some growers have

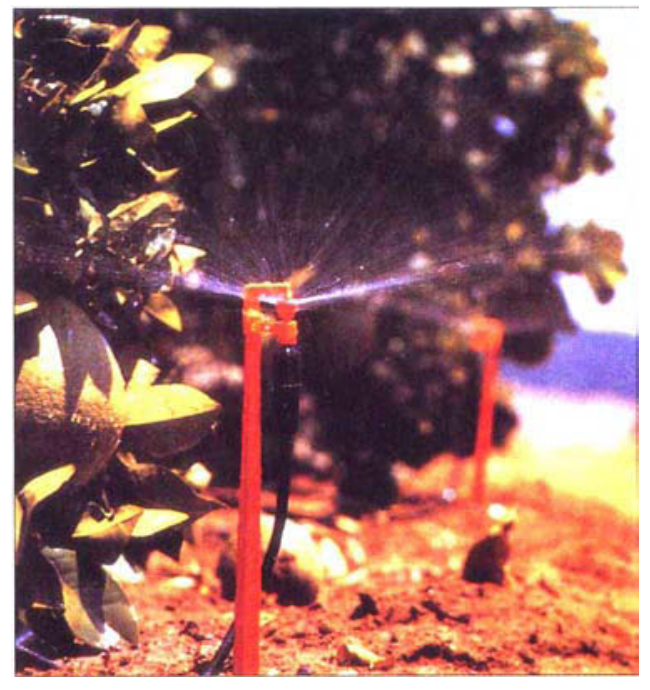

Crop type may influence adoption of lowvolume irrigation technology such as microsprinklers.

stated that use of multiple drip emitters for each tree, and a long transition period using both gravity and lowpressure systems, allows technology switching without damaging crops or making them susceptible to disease.

The District estimates groundwater pumping costs based on pumping depths of groundwater and the energy cost for the size of pump needed to lift water from a given depth. The variable price for surface water is the use fee that the District charges for each acre-foot that is actually delivered; on average this is $\$ 25$ less per acre-foot
TABLE 1. Irrigation technology and acreage by crop

\begin{tabular}{|c|c|c|c|c|}
\hline \multirow[b]{2}{*}{ Crop } & \multirow[b]{2}{*}{ Acreage } & \multicolumn{3}{|c|}{$\begin{array}{l}\text { Acreage in } \\
\text { irrigation technology }\end{array}$} \\
\hline & & Gravity & $\begin{array}{c}\text { High- } \\
\text { pressure }\end{array}$ & $\begin{array}{l}\text { Low- } \\
\text { pressure }\end{array}$ \\
\hline & & & $\%$ & . \\
\hline Citrus & 12,065 & 15 & 1 & 84 \\
\hline Deciduous & 11,700 & 27 & 33 & 40 \\
\hline Grapes & 23,665 & 61 & 2 & 37 \\
\hline Truck crops & 12,856 & 22 & 73 & 5 \\
\hline Potatoes & 14,721 & 1 & 98 & 1 \\
\hline Cotton & 17,286 & 1 & 99 & 0 \\
\hline Total & 92,293 & 25 & 49 & 26 \\
\hline
\end{tabular}

TABLE 2. Irrigation technology and acreage by variable water price

\begin{tabular}{|c|c|c|c|c|}
\hline \multirow[b]{2}{*}{$\begin{array}{l}\text { Range of variable } \\
\text { water price }\end{array}$} & \multirow[b]{2}{*}{ Acreage } & \multicolumn{3}{|c|}{$\begin{array}{c}\text { Acreage in } \\
\text { irrigation technology }\end{array}$} \\
\hline & & Gravity & $\begin{array}{c}\text { High- } \\
\text { pressure }\end{array}$ & $\begin{array}{l}\text { Low- } \\
\text { pressure }\end{array}$ \\
\hline & & & $\%$.. & \\
\hline Less than $\$ 30$ & 20,304 & 27 & 49 & 24 \\
\hline$\$ 31$ to $\$ 45$ & 19,382 & 17 & 48 & 35 \\
\hline$\$ 46$ to $\$ 60$ & 34,148 & 27 & 49 & 24 \\
\hline$\$ 61$ to $\$ 75$ & 13,844 & 21 & 33 & 46 \\
\hline Greater than $\$ 75$ & 4,615 & 27 & 59 & 14 \\
\hline
\end{tabular}




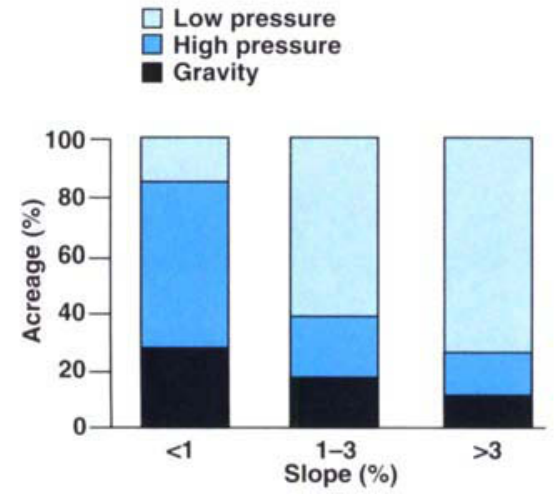

Fig. 1. Irrigation technology by slope.

than groundwater pumping costs. Growers in the District pay a relatively high variable price for water. In 1993 the price ranged from $\$ 12$ to $\$ 57$ per acre-foot for surface water and from $\$ 40$ to $\$ 88$ per acre-foot for groundwater. However, the District adjusts the fixed fee for surface water so that the total price for ground and surface water are approximately the same, ranging from $\$ 50$ to $\$ 110$. The price of both ground and surface water in the District has increased since 1993.

The wide range of water prices in the District creates an ideal forum for analyzing the effect of price on irrigation technology choices. Table 2 shows that there is not a clear pattern of technology choice as water price increases from less than $\$ 30$ to more than $\$ 75$ per acre-foot. For example, low-pressure irrigation is used on $24 \%$ of the acreage that receives water at less than $\$ 30$ per acre-foot. The acreage increases to $35 \%$

TABLE 3. Effect of variable on probability of technology adoption

\begin{tabular}{|c|c|c|c|}
\hline & \multicolumn{3}{|c|}{ Irrigation technology } \\
\hline & Gravity & High-pressure & Low-pressure \\
\hline Water price & - & - & + \\
\hline Field size & - & + & + \\
\hline Soil permeability & - & + & + \\
\hline Field slope & - & + & + \\
\hline Receive surface water & - & - & + \\
\hline \multicolumn{4}{|l|}{ Crops } \\
\hline Citrus & - & - & + \\
\hline Deciduous & - & - & + \\
\hline Grapes & + & - & + \\
\hline $\begin{array}{l}\text { Truck crops } \\
\text { (including potatoes) }\end{array}$ & - & + & - \\
\hline
\end{tabular}

in the next price range, but falls to $14 \%$ for those acres that pay more than $\$ 75$ per acre-foot of water. However, it is important to note that only $5 \%$ of the cultivated acreage in the District faces a water price of more than $\$ 75$ per acre-foot, so this has only a small effect on our results.

Soil permeability and field slope are the two dimensions used to define land quality. These data were collected from the Kern County office of the U.S. Natural Resource Conservation Service. The data provide soil type for each quarter section. District land maps were used to place each field in the corresponding quarter section. Permeability and slope were given in inches per hour and percent, respectively. Both permeability and slope were given in ranges; the midpoint was taken and used to construct weighted averages for each quarter section.

Figure 1 shows the distribution of irrigation technology for given slope ranges. Note that as slope increases the percent of acreage under lowpressure irrigation also increases. This indicates that the grower's irrigation technology choice is conditioned on land characteristics. The effect of permeability on technology choice is not as distinct.

These data are used with a statistical model of technology adoption. The crops, irrigation technology and agronomic diversity of the District are especially well suited to give insight into the constraints that growers face when responding to water policy.

\section{Model results}

The model predicts the probability that a given irrigation technology is adopted as a function of crop, land characteristics, water source and water price. The results in table 3 show whether a specific variable increases $(+)$, decreases (-) or does not affect that probability of technology adoption.

The results indicate that the adoption of irrigation technologies is highly dependent on crop type. After controlling for field-specific factors, highpressure systems are less likely to be adopted on all perennial crop (grapes, citrus and deciduous); low-pressure technologies are more likely to be adopted on all perennial crops (table 3 ). This finding can be attributed to the physical interaction between highpressure sprinklers and perennial crops. High-pressure sprinklers disperse water over a large area, saturating the crop, which can cause disease in many perennial crops as well as some annual crops. Therefore highpressure sprinklers are not used on some perennial crops. Under gravity irrigation, the results are less pronounced but still evident. This corresponds with the knowledge that many perennial crops can still be competitively grown with the traditional technology under the right growing conditions. However, we found that the choice to grow annual crops increases the probability of adopting highpressure irrigation technologies.

The results also show that the adoption of low-pressure technology is highly sensitive to water price. This finding agrees with standard economic theory that water-saving technologies are adopted as the price of water increases. However, this does not hold true for high-pressure technology, which has a negative sign. In the study area, high-pressure irrigation has been in use since the late 1950s. Currently high-pressure irrigation is near the top of its diffusion curve; that is, it has been adopted on most crops that it can be productively used on. For example, potatoes are grown almost exclusively under highpressure irrigation (table 1). As a result, the adoption of high-pressure irrigation is not sensitive to changes in water price in the District. Instead, the results indicate that growers have begun to switch from high-pressure to low-pressure irrigation. In fact, as the 
price of water has increased over time, growers have begun experimenting with different types of low-pressure irrigation on crops that previously used high-pressure irrigation. This suggests that the growers' response to water policy depends on where a given technology is on the diffusion curve - a factor that varies substantially throughout California.

For a better understanding of the effect of water cost on adoption of irrigation technologies, we calculated and graphed the change in adoption probability as a function of water price. All other variables were held at their mean values. We observed that as the price of water increases, growers switch from both gravity and highpressure to low-pressure irrigation technologies (fig. 2).

Although we found that highpressure technologies are not as sensitive to land quality as low-pressure or gravity irrigation technologies, the results show that land characteristics are important to technology choice. Low-pressure irrigation is highly dependent on land-quality characteristics, especially field slope. The introduction of low-pressure technologies allowed cultivation of land that previously had been difficult and costly to farm due to its topography. Variations in soil permeability and slope have a dramatic effect on gravity and lowpressure irrigation adoption (figs. 3 and 4). This also indicates that growers who have relatively flat fields with nonpermeable soils are likely to continue using gravity technologies rather than adopt low-pressure technologies.

Other economists have shown theoretically that modern irrigation technologies are less likely to be adopted on fields with surface water supplies rather than groundwater supplies. This is because it is easier to provide the additional pressure required for pressurized systems with groundwater pumping. This holds true for highpressure but not for low-pressure irrigation. There are two explanations for this. First, the District supplies pressurized water to many of its growers. However, the pressure is not consistent throughout the District and is of- ten only high enough to run a low-pressure system. Second, there is an important issue of reliability of water supply that has not been addressed. The District's water contracts with the U.S. Bureau of Reclamation guarantee it only a small amount of Class 1 priority surface water supply each year. Although historically the District has met water demands by pumping groundwater with District-owned wells, surface water is perceived as a less reliable source of water than ground water because it is under bureaucratic control. Therefore the adoption of low-pressure irrigation in areas that receive surface water may be intended to minimize the risk of an uncertain water supply to perennial crops. This is not the case with high-pressure irrigation, which is used primarily on annual crops that can be taken out of production if the water supply is limited.

\section{Policy implications}

Our model shows that growers behave in a manner consistent with economic theory. The adoption of various irrigation technologies can be partially explained by a model based on an assumption of profit maximization. This observation implies that agricultural water use can be controlled by changing economic incentives such as water price and availability. However, growers face rigid constraints related to their land and crop experience that condition their response to price incentives. As a result, policy makers should expect a wide variation in irrigation technology choices among growers in response to water policy.
We have verified that there are many determinants of irrigation technology choice, including crop choice and soil characteristics, in addition to water price and availability. Crop choice appears to have a profound effect on technology choice, as some technologies may be incompatible with some types of crops. Therefore it is important to consider the crops grown in a region when implementing policy. Field characteristics are also important. For example, if a field is flat and has low water permeability, a grower is unlikely to switch to a modern irrigation technology. In such a case, increases in price may simply reduce retained earnings, with little or no effect on irrigation technology adoption.

In particular we found that lowpressure irrigation technologies are 


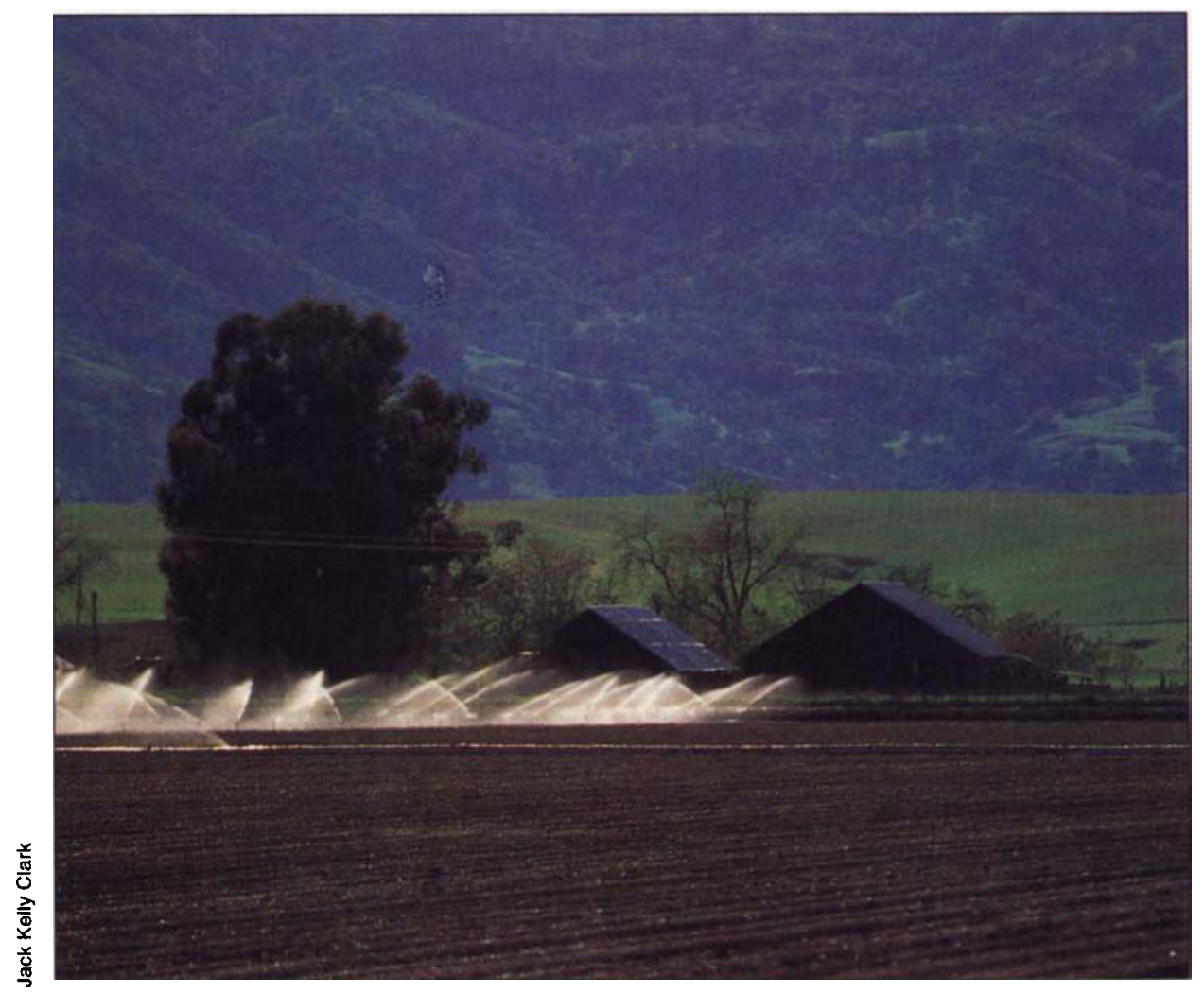

High-pressure sprinklers disperse water over a large area, which may make them a more desirable choice than a low-volume irrigation system for large fields.

more likely to be adopted as water price increases. Adoption of lowpressure systems is especially sensitive to water price in the District because there are many crops grown with gravity irrigation that can be grown with low pressure. In this case an increase in water savings, in addition to other benefits associated with low-pressure irrigation, may make adoption a cost-effective response to higher water prices.

The impact of changing how irrigation water is priced and delivered has an important distributional component. Whether or not a grower adopts irrigation technology in response to price increases depends on crop, topography and soil characteristics. However, using water price rather than best management practices as a policy tool allows growers flexibility in their response, which minimizes policy impacts. As a result, technology adoption that stems from changes in water-pricing policy will be gradual. This will minimize policy impacts because growers will be able to make the decision of when to adopt, depending on their own particular circumstances. Best management practices that dictate agricultural technology choices will have potentially large impacts on California growers. A policy that mandates when a given technology is to be adopted will probably be inefficient because it does not allow for the diversity among growers. Our results show that California's highly diverse climate and soil conditions influence irrigation technology choices, and a "one-sizefits-all" policy mandating adoption of modern technologies is likely to be highly inefficient.

G. Green is Asșistant Professor, Department of Agricultural Economics, Washington State University, Pullman, WA; D. Sunding is Assistant Professor, D. Zilberman is Professor, and D. Parker is Extension Economist, Department of Agricultural and Resource Economics, UC Berkeley; C. Trotter is formerly Manager-Engineer and S. Collup is currently Manager-Engineer, Arvin Edison Water Storage District, Arvin.

The authors would like to thank Helen Kim, Hodge Black and all of the staff at the Arvin Edison Water Storage District for their assistance with this study. The research was funded by a Challenge Grant from the U.S. Bureau of Reclamation. Any opinions, findings, conclusions or recommendations expressed are those of the authors and do not necessarily reflect the views of the Bureau or the Arvin Edison Water Storage District. Any omissions or errors are the responsibility of the authors.

\section{CALIFORNIA AGRICULTURE ASSOCIATE EDITORS}

Animal, Avian, Aquaculture and Veterinary Sciences Bennie I. Osburn

\section{Economics and Public Policy}

Harold O. Carter

Alvin Sokolow

\section{Food and Nutrition}

Barbara Schneeman Eunice Williamson

\section{Human and Community Development}

Linda M. Manton

Karen $\mathbf{P}$, Varcoe
Land, Air \& Water Sciences

Garrison Sposito

Henry J. Vaux, Jr.

\section{Natural Resources}

Daniel W. Anderson Richard B. Standiford

\section{Pest Management}

Michael Rust Frank Zalom

Plant Sciences

Calvin O. Qualset

G. Steven Sibbett

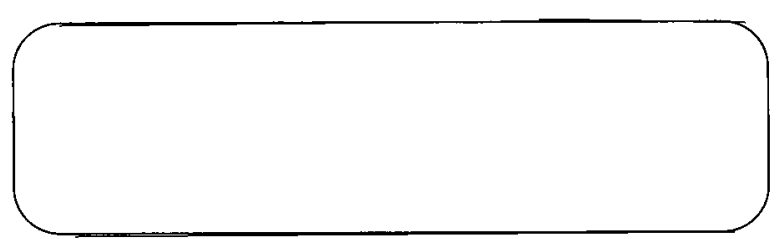

